\title{
Potential genetic modifiers for somatic EGFR mutation in lung cancer: a meta- analysis and literature review
}

\author{
Yue I. Cheng ${ }^{1,2+}$, Yun Cui Gan ${ }^{1 \dagger}$, Dan Liu', Michael P. A. Davies², Wei Min Li ${ }^{1 *}$ and John K. Field ${ }^{2}$
}

\begin{abstract}
Background: Accumulating evidence indicates inherited risk in the aetiology of lung cancer, although smoking exposure is the major attributing factor. Family history is a simple substitute for inherited susceptibility. Previous studies have shown some possible yet conflicting links between family history of cancer and EGFR mutation in lung cancer. As EGFR-mutated lung cancer favours female, never-smoker, adenocarcinoma and Asians, it may be argued that there may be some underlying genetic modifiers responsible for the pathogenesis of EGFR mutation.

Methods: We searched four databases for all original articles on family history of malignancy and EGFR mutation status in lung cancer published up to July 2018. We performed a meta-analysis by using a random-effects model and odds ratio estimates. Heterogeneity and sensitivity were also investigated. Then we conducted a second literature research to curate case reports of familial lung cancers who studied both germline cancer predisposing genes and their somatic EGFR mutation status; and explored the possible links between cancer predisposing genes and EGFR mutation.
\end{abstract}

Results: Eleven studies have been included in the meta-analysis. There is a significantly higher likelihood of EGFR mutation in lung cancer patients with family history of cancer than their counterparts without family history, preferentially in Asians $(\mathrm{OR}=1.35[1.06-1.71], P=0.01)$, those diagnosed with adenocarcinomas $((\mathrm{OR}=1.47[1.14-$ 1.89], $P=0.003$ ) and those with lung cancer-affected relatives (first and second-degree: $\mathrm{OR}=1.53[1.18-1.99], P=$ 0.001; first-degree: $\mathrm{OR}=1.76[1.36-2.28, P<0.0001])$. Familial lung cancers more likely have concurrent EGFR mutations along with mutations in their germline cancer predisposition genes including EGFR T790 M, BRCA2 and TP53. Certain mechanisms may contribute to the combination preferences between inherited mutations and somatic ones.

Conclusions: Potential genetic modifiers may contribute to somatic EGFR mutation in lung cancer, although current data is limited. Further studies on this topic are needed, which may help to unveil lung carcinogenesis pathways. However, caution is warranted in data interpretation due to limited cases available for the current study.

Keywords: Lung cancer, EGFR mutation, Family history of cancer, Inherited susceptibility, Cancer predisposition genes, EGFR T790 M, BRCA, TP53, DNA repair, Lung cancer aetiology

\footnotetext{
* Correspondence: weimin003@163.com

†Yue I. Cheng and Yuncui Gan contributed equally to this work.

'Department of Respiratory and Critical Care Medicine, West China Hospital,

Sichuan University, Chengdu 610041, China

Full list of author information is available at the end of the article
}

(c) The Author(s). 2019 Open Access This article is distributed under the terms of the Creative Commons Attribution 4.0 International License (http://creativecommons.org/licenses/by/4.0/), which permits unrestricted use, distribution, and reproduction in any medium, provided you give appropriate credit to the original author(s) and the source, provide a link to the Creative Commons license, and indicate if changes were made. The Creative Commons Public Domain Dedication waiver (http://creativecommons.org/publicdomain/zero/1.0/) applies to the data made available in this article, unless otherwise stated. 


\section{Background}

Lung cancer is the most frequently diagnosed cancer and also the leading cause of cancer-related deaths over the world [1]. Despite advances in molecular, pathological and biological research, the pathogenesis of lung cancer has not yet been fully elucidated. Though the predominant risk factor, smoke exposure has widely differing attribution to lung cancer risk across different ethnicities, e.g. over $80 \%$ in both males and females in the US [2] and UK [3], but only $57.5 \%$ in males and $11.5 \%$ in females in China [4]. These significant differences indicate lung cancer aetiology is significantly impacted by other risk factors including inherited susceptibility.

Family history is a simple substitute for genetic susceptibility, easily assessed and less technologically demanding (although limited by societal differences in family size). Multiple epidemiological studies [5-9] demonstrated that family aggregation of malignancies would increase individuals' lung cancer risk. Some critics argued that the family aggregation of lung cancer might have resulted from a shared environment, such as smoking exposure among family members; because most of the cancers clustering in probands' families are smokingrelated [10], and gene-smoking interactions could not be neglected in lung tumorigenesis [11]. However, evidence on the heritability of lung cancer is also accumulating. Epidemiologically, family history of lung cancer still had a significantly increased risk in never-smoker probands [7], especially in Asians after adjusting confounders including smoking [9, 12]. Genetically, recent genomewide association studies (GWAS) or sequencing studies of lung cancer unveiled a role of inherited susceptibility component overriding that of smoking behaviour [13]. Some significant risk loci have been found to be genome-wide significantly associated with never-smoker lung cancers $[14,15]$.

Recently, many potential cancer predisposition genes (CPGs) or susceptibility loci have been revealed by investigating familial lung cancers or lung cancerclustering families. However, the currently uncovered CPG mutations have been estimated to attribute to only $\sim 3 \%$ of all cancers [16]. Relevant evidence on CPGs is much more limited compared to somatic mutations in the era of whole-genome sequencing $[16,17]$.

Since its first discovery in lung adenocarcinoma in 2004, somatic EGFR mutation - one of the most important and targetable driver mutations found in non-small cell lung cancer (NSCLC) - has been extensively validated as an effective indicator of sensitivity to EGFR tyrosine kinase inhibitors (TKIs), as well as a prognosticator for patients [18]. It is confirmed that exon 19 deletion and L858R point mutation in exon 21 are the most frequently mutated subtypes (the "common mutations"), accounting for 45 and $35 \%$ of all the EGFR-mutated NSCLC cases, respectively [19]. Rare mutations have less evidence on TKI sensitivity and clinical responsiveness than the common ones, while some consensus has been achieved via individual or selective analysis: mutations occurring within exons 18 to 21 usually confers sensitivity to EGFR TKIs, except those within exon 20, such as T790 $\mathrm{M}$ and exon 20 insertions [18]. It's of note, EGFRmutated lung cancers generally have a different epidemiological profile from the EGFR wild-type ones, the former more likely to be non-smokers (vs smokers: $37.6 \% \sim 62.5 \%$ vs $8.4 \% \sim 35.9 \%$ varying by ethnicity), East Asians (vs Westerns: $47.9 \%$ vs $19.2 \%$ in ADCs) and lung adenocarcinomas (vs SCCs: $47.9 \%$ vs $4.6 \%$ in Asians) [20-22], which may indicate distinct modulations of relevant variables in tumorigenesis.

Since lung cancers with a family history may indicate a potentially differed genetic background from sporadic cases, it is interesting to investigate if there is a relationship between family history of cancer and EGFR mutations in lung cancer patients, both of which participate in tumorigenesis. To date, observational studies reported conflicting relationships, either positive or neutral, between family history and the presence of EGFR mutation in lung cancer patients. Given the contradictory epidemiological findings and the potential implication in lung carcinogenesis, we conducted a meta-analysis to pool the risk estimates from previous studies focusing on family history of cancer and somatic EGFR mutation; then by a second literature research, we summarized familial lung cancer cases with both potential CPGs and somatic EGFR mutation status reported to help to throw a light on this topic.

\section{Methods}

Meta-analysis of family history on somatic EGFR mutation We followed the guidelines of the Meta-analysis of Observational Studies in Epidemiology (MOOSE) group for reporting [23]. We searched PubMed, EMBASE, Web of Science and Cochrane Library by using a combination of free text and medical subject heading (MESH) terms related to lung cancer, EGFR and family history (Detailed searching strategies in Additional file 1: Table S1). Hand searching the bibliography of relevant articles was also used.

Our inclusion criteria were as follows: [1] Case-control study, cohort study and other studies of lung cancer patients with EGFR mutation status detected/reported [2]; Odds ratios (in case-control studies), relative ratios (in cohort studies) reported relative to a family history of cancer, or of sufficient information to calculate them. If there were several eligible publications derived from the same dataset, the one with the largest sample size was included. Studies with limited or incomplete data 
including case studies, studies with only EGFR mutant cases or incomplete information associating with both EGFR mutation status and family history were excluded.

Two independent authors (YIC and YCG) first reviewed all the titles/abstracts to find the potentially related studies, then had a full view of these potentially related studies and selected the eligible studies based on the inclusion/exclusion criteria above. Any discrepancies were resolved by consensus after discussion.

The two reviewers independently extracted information concerning study design, year of publication, study size, study duration, inclusion/exclusion criteria, subjects' characteristics (age, gender, ethnicity, lung cancer histology, smoking status, family history of lung cancer/other cancer in first/second-degree relatives) at the diagnosis of lung cancer, EGFR mutations and detection methods, odds ratio (OR) or risk ratio estimates and the corresponding 95\% CIs. The Newcastle-Ottawa scale was used to assess the quality of each included study [24].

Forest plots were generated for meta-analytic estimates by using Mantel-Haenszel (MH) method and randomeffects models. Inverse Variance (IV) method was used when only estimates and their standard errors were available in the original studies. Heterogeneity was assessed by using Cochran's Q and $\mathrm{I}^{2}$-statistic. To test the robustness of the estimates, we performed a sensitivity analysis by subgrouping studies. Publication bias was evaluated by applying the funnel plot [24]. We used RevMan 5.3 to perform all the analysis.

\section{Literature research for underlying mechanisms on somatic EGFR mutation}

To further elucidate the topic, we searched PubMed and Web of Science Core Collection using a combination of keywords and/or MeSH terms associating with "lung cancer", "family history" and "germline mutation" (detailed searching strategies in Additional file 1: Table S2). Then we concluded current papers associating with lung cancer-clustering families which reported their tumour somatic EGFR mutation status. Our inclusion criteria were: 1) potential CPGs were investigated and reported in the index case of lung cancer; 2) CPGs were also detected and validated in other family members besides the proband; 3) somatic EGFR mutations were reported in the lung tumours in the probands and/or other family members. No ethical approval was needed for the current study.

\section{Results}

\section{Meta-analysis}

After removing duplicates and the initial screening of titles and abstracts, 120 papers were potentially related and undergone through a full-text review. Ninety-two papers had incomplete or limited data, fifteen were meeting abstracts, one was non-English, and another studied the same population as one of the eligible papers (more detailed information in the latter). Thus, 11 original studies were included (Fig. 1). Quality assessment results of each study were shown in Additional file 1: Tables S3-S4.

Table 1 showed the main characteristics of the studies included in the current meta-analysis [25-35]. Ten of them were cohort studies and one was a case-control study. Most of the studies focused on non-small cell lung cancers (NSCLCs) or lung adenocarcinomas (ADCs). There were quite a number of differences in definitions of EGFR positive mutation and family history, detection methods and composition of the study population. Due to a very high heterogeneity by pooling all the studies $\left(\mathrm{I}^{2}=78 \%, P<0.000\right)$, we performed the funnel plot and excluded the outlier study by Cheng et al. (2015) [25] in our analysis afterwards (Additional file 1: Figures S1-S2).

Figure 2 provided the "overall" likelihood of EGFR mutation status in lung cancer patients with family history of any cancer (FH_Any) compared to those without from the remaining ten studies. "Overall" estimates of FH_Any here referred to the total effects by pooling the studies without differentiating family history of all cancers, lung cancer or other non-lung cancers. There was a marginal significance $(\mathrm{OR}=1.23[1.00-1.50], P=0.05)$ with an intermediate heterogeneity among studies $\left(\mathrm{I}^{2}=\right.$ $47 \%, P=0.05$ ). When restricted to Asian countries (eight studies), the difference became significant (OR = 1.35[1.06-1.71], $P=0.01$ ) (Fig. 2a). In lung adenocarcinoma (ADC) patients with FH_Any, EGFR was more likely mutated than those without $(\mathrm{OR}=1.47$ [1.14-1.89], $P=0.003$ ) (Fig. 2b). Marginal significance was also observed in patients with cancer in their first-degree relatives than their FH_Any-absent counterparts (OR = 1.37[0.99-1.89], $P=0.06$ ) (Fig. 2c). However, there were no significant findings when limiting patients to females, never-smokers or those having FH_Any yet with both their first- and second-degree relatives included, possibly due to much less data in these subgroups.

There was a significantly higher proportion of EGFR mutation in patients with family history of lung cancer (FHLC) than those without (OR $=1.53[1.18-1.99], P=$ 0.001) (Fig. 3a), including in analyses limited to those who had lung cancer in their first degree relatives $(\mathrm{OR}=$ 1.76 [1.36-2.28], $P<0.0001$ ) (Fig. 3a). The association between EGFR mutation and FHLC-positive cases remained significant when limited to those diagnosed as NSCLCs $\quad(\mathrm{OR}=1.86[1.35-2.57], \quad P=0.0001) \quad$ (Fig. 3b). Only one study reported data of EGFR mutation specifically in ADC patients with FHLC, which indicated a significantly higher possibility of mutation than those absent of FHLC $(\mathrm{OR}=1.51[1.04-2.19], P=0.03)$. The 


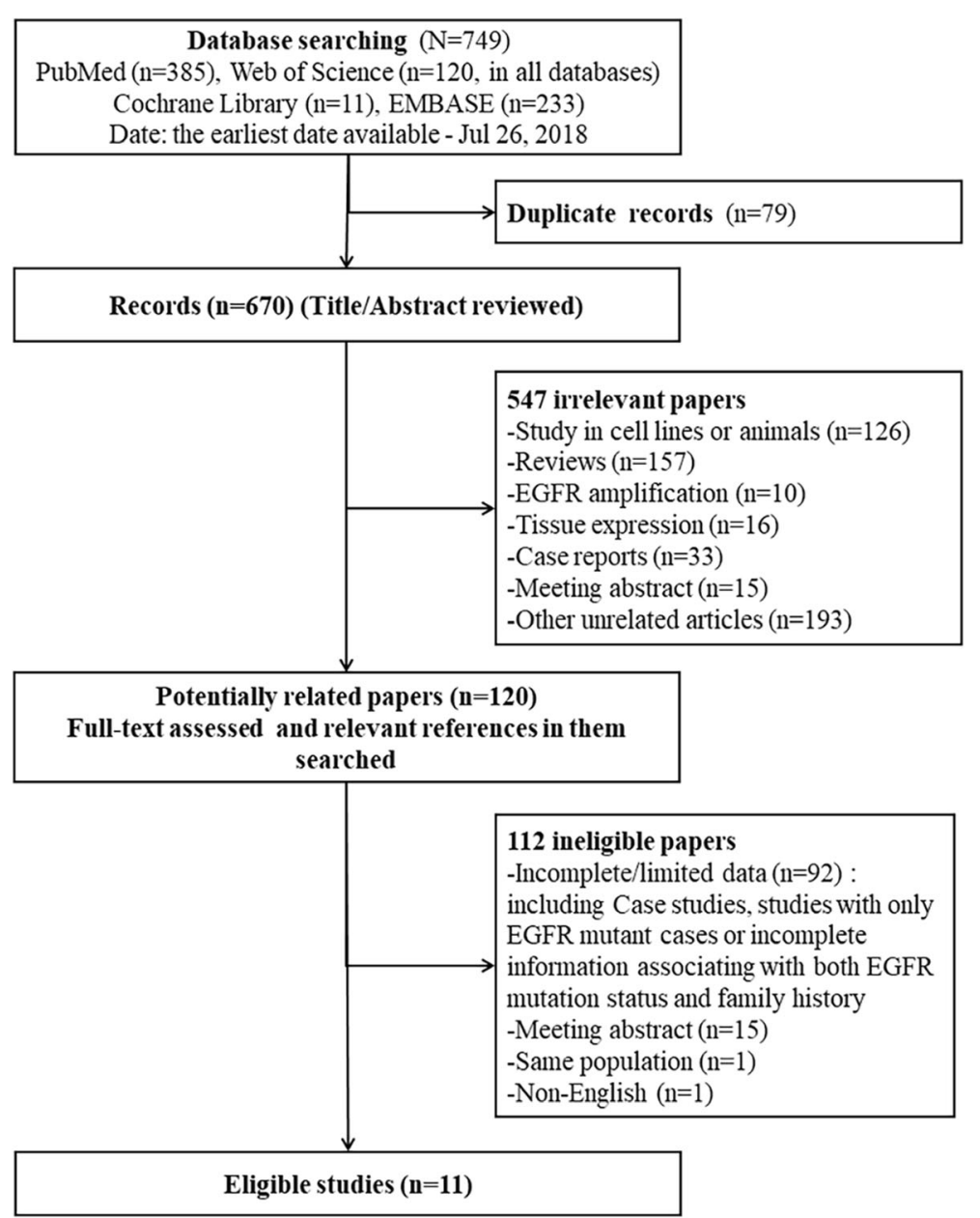

Fig. 1 Flowchart of study design for the meta-analysis

association between the two variables was not altered greatly if only Asian patients were included (Data not shown since neither of the two excluded non-Asian studies showed significant results). Further subgroup analysis of EGFR mutation status in patients with/without $\mathrm{FH}$ of all cancers or other non-lung cancers did not demonstrate any remarkable difference between subgroups tested (Data not shown).

\section{Results of the second literature search}

In total, there were 41 lung cancer cases in 29 families eligible for our second analysis (Tables 2 and 3). The median onset age was 57 years-old (range 22-78). Females (31/41, 75.6\%) and never-smokers (24/41, $58.5 \%)$ predominated in the curated cases. Almost all $(35 / 41,85.3 \%)$ of the histology in lung cancer patients were ADCs; the remaining five patients were diagnosed as NSCLCs (uncategorized) and another one was SCC. In this dataset, there were eight White and seven Asian families. Five of the White families inherited the EGFR gene; while CPGs in the Asian families were more scattered (but report bias could not be excluded here).

Fourteen families (of 29, 48.3\%) reported germline EGFR mutations, and eight of them carried the T790 M mutation [36-42]. Other germline EGFR mutations included $\mathrm{R} 776 \mathrm{H}$ [43] and V769 M [44] in exon 20, and V834 L [47] and V843I [45, 46] in exon 21. Nine index patients (of 29, 31.0\%) had inherited TP53 mutations, among whom two had another concurrent germline mutation, respectively (Case No. 38 and Case No. 40) (Table 2).

Ten (of 29, 34.5\%) families had multiple lung cancers diagnosed or multiple lung nodules found in the probands or among their family members, which made in total over 78 tumours across the dataset. Specifically, six families (of 14, 42.9\%) with multiple lung lesions harboured inherited EGFR mutations.

Among all the 78 tumours, fifty-four $(\sim 69.2 \%)$ of these tumours carried a subsequent positive somatic mutation. In the subgroup of inherited EGFR mutations, a secondary activating mutation occurred in $70.2 \%$ (33/47) of the 


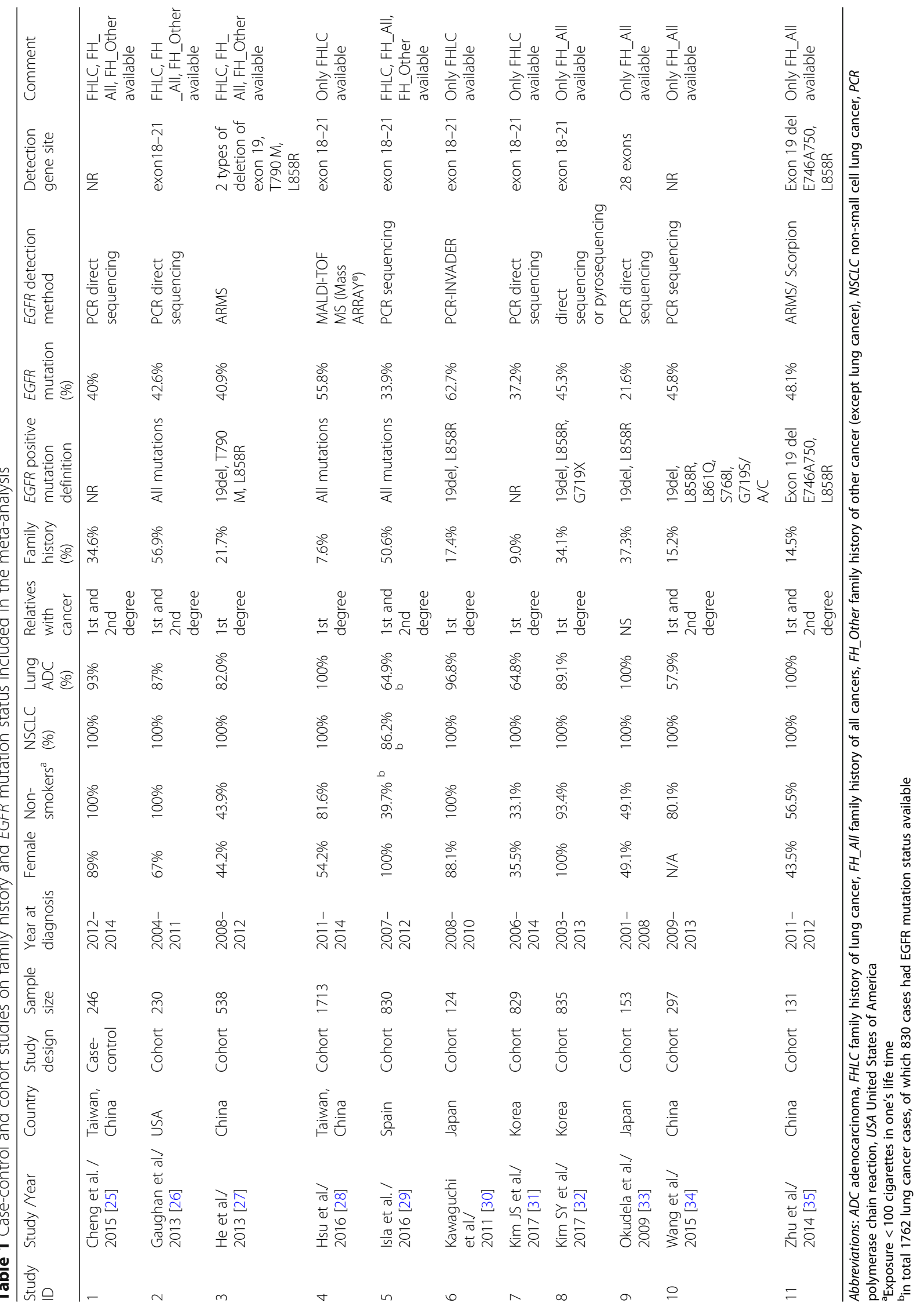




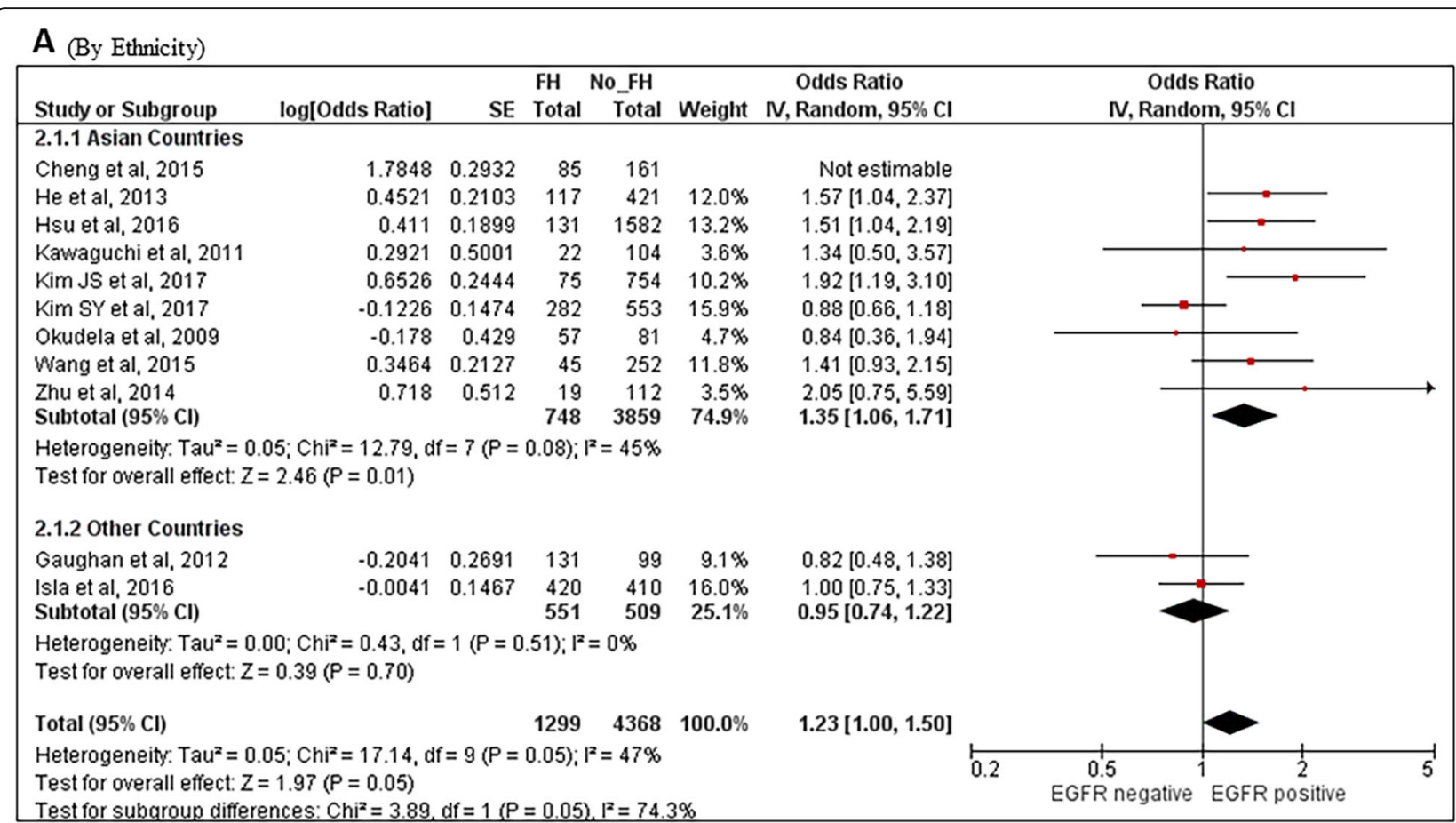

B (Adenocarcinoma)

\begin{tabular}{|c|c|c|c|c|c|c|c|c|c|}
\hline \multirow{2}{*}{$\begin{array}{l}\text { Study or Subgroup } \\
\text { He et al, } 2013\end{array}$} & log[Odds Ratio] & \multicolumn{2}{|c|}{$\begin{array}{l}\text { FH I } \\
\text { SE Total } \\
\end{array}$} & $\begin{array}{l}\text { No FH } \\
\text { Total }\end{array}$ & Weight & \multirow{2}{*}{$\begin{array}{c}\text { Odds Ratio } \\
\text { IV, Random, } 95 \% \mathrm{Cl}\end{array}$} & \multicolumn{3}{|c|}{$\begin{array}{c}\text { Odds Ratio } \\
\mathrm{N}, \text { Random, } 95 \% \mathrm{Cl}\end{array}$} \\
\hline & 0.4725 & 0.2271 & 102 & 339 & $32.5 \%$ & & & & \\
\hline Hsu et al, 2016 & 0.411 & 0.1899 & 131 & 1582 & $46.5 \%$ & $1.51[1.04,2.19]$ & & & $\longrightarrow$ \\
\hline Kawaguchi et al, 2011 & 0.1655 & 0.552 & 0 & 0 & $5.5 \%$ & $1.18[0.40,3.48]$ & & & \\
\hline Okudela et al, 2009 & -0.178 & 0.429 & 57 & 81 & $9.1 \%$ & $0.84[0.36,1.94]$ & & & \\
\hline Zhu et al, 2014 & 0.718 & 0.512 & 19 & 112 & $6.4 \%$ & $2.05[0.75,5.59]$ & & & \\
\hline Total $(95 \% \mathrm{Cl})$ & & & 309 & 2114 & $100.0 \%$ & $1.47[1.14,1.89]$ & & & \\
\hline \multicolumn{5}{|c|}{$\begin{array}{l}\text { Heterogeneity: } \mathrm{Tau}^{2}=0.00 ; \mathrm{Chi}^{2}=2.47, \mathrm{df}=4(P=0.65) ; \mathrm{I}^{2}=0 \% \\
\text { Test for overall effect: } Z=2.96(P=0.003)\end{array}$} & & & 0.2 & $\begin{array}{cc}0.5 & 1 \\
\text { EGFR negative }\end{array}$ & 12 \\
\hline
\end{tabular}

C (Cancer in first-degree relatives)

\begin{tabular}{|c|c|c|c|c|c|c|c|c|c|c|}
\hline Study or Subgroup & log[Odds Ratio] & SE & $\begin{array}{l}\text { FH } \\
\text { Total }\end{array}$ & $\begin{array}{l}\text { No FH } \\
\text { Total }\end{array}$ & Weight & $\begin{array}{c}\text { Odds Ratio } \\
\mathrm{N}, \text { Random, } 95 \% \mathrm{Cl}\end{array}$ & & $\begin{array}{r}\text { Odds } \mathrm{r} \\
\mathrm{N} \text {, Randon }\end{array}$ & $\begin{array}{l}\text { Ratio } \\
\mathrm{m}, 95 \% \mathrm{Cl}\end{array}$ & \\
\hline He et al, 2013 & 0.4521 & 0.2103 & 117 & 421 & $21.9 \%$ & $1.57[1.04,2.37]$ & & & $\longrightarrow$ & \\
\hline Hsu et al, 2016 & 0.411 & 0.1899 & 131 & 1582 & $23.5 \%$ & $1.51[1.04,2.19]$ & & & & \\
\hline Kawaguchi et al, 2011 & 0.2921 & 0.5001 & 22 & 104 & $8.2 \%$ & $1.34[0.50,3.57]$ & & & & \\
\hline Kim JS et al, 2017 & 0.6526 & 0.2444 & 75 & 754 & $19.5 \%$ & $1.92[1.19,3.10]$ & & & & \\
\hline Kim SY et al, 2017 & -0.1226 & 0.1474 & 282 & 553 & $26.9 \%$ & $0.88[0.66,1.18]$ & & & - & \\
\hline Total $(95 \% \mathrm{Cl})$ & & & 627 & 3414 & $100.0 \%$ & $1.37[0.99,1.89]$ & & & & \\
\hline \multicolumn{6}{|c|}{$\begin{array}{l}\text { Heterogeneity: } \operatorname{Tau}^{2}=0.08 ; \mathrm{Chi}^{2}=10.74, \mathrm{df}=4(P=0.03) ; \mathrm{I}^{2}=63 \% \\
\text { Test for overall effect: } Z=1.91(P=0.06)\end{array}$} & & 0.2 & $\begin{array}{c}0.5 \\
\text { EGFR nagative }\end{array}$ & EGFR posit & 5 \\
\hline
\end{tabular}

Fig. 2 Forest plots for family history of any cancer and the risk of EGFR positive mutation. a Overall and by country: $\mathbf{b}$ in lung adenocarcinoma patients; and $\mathbf{c}$ patients with family history of any cancer in first-degree relatives. FH, family history; IV, Inverse Variance method. Cl, confidence interval

germline EGFR mutation carrier lung cancer cases; similarly, in lung cancers diagnosed in germline T790 M mutation carriers, the proportion of a secondary activating mutation was 73\% [40]. Both of the concurrence rates above were higher than that reported in the sporadic NSCLCs (10\% 35\%) [61]. About a half of them were EGFR L858R mutation; $48.1 \%(26 / 54)$ in all the curated inherited lung cancers and $57.6 \%(19 / 33)$ in the inherited EGFR subgroup (Table 3 ). 


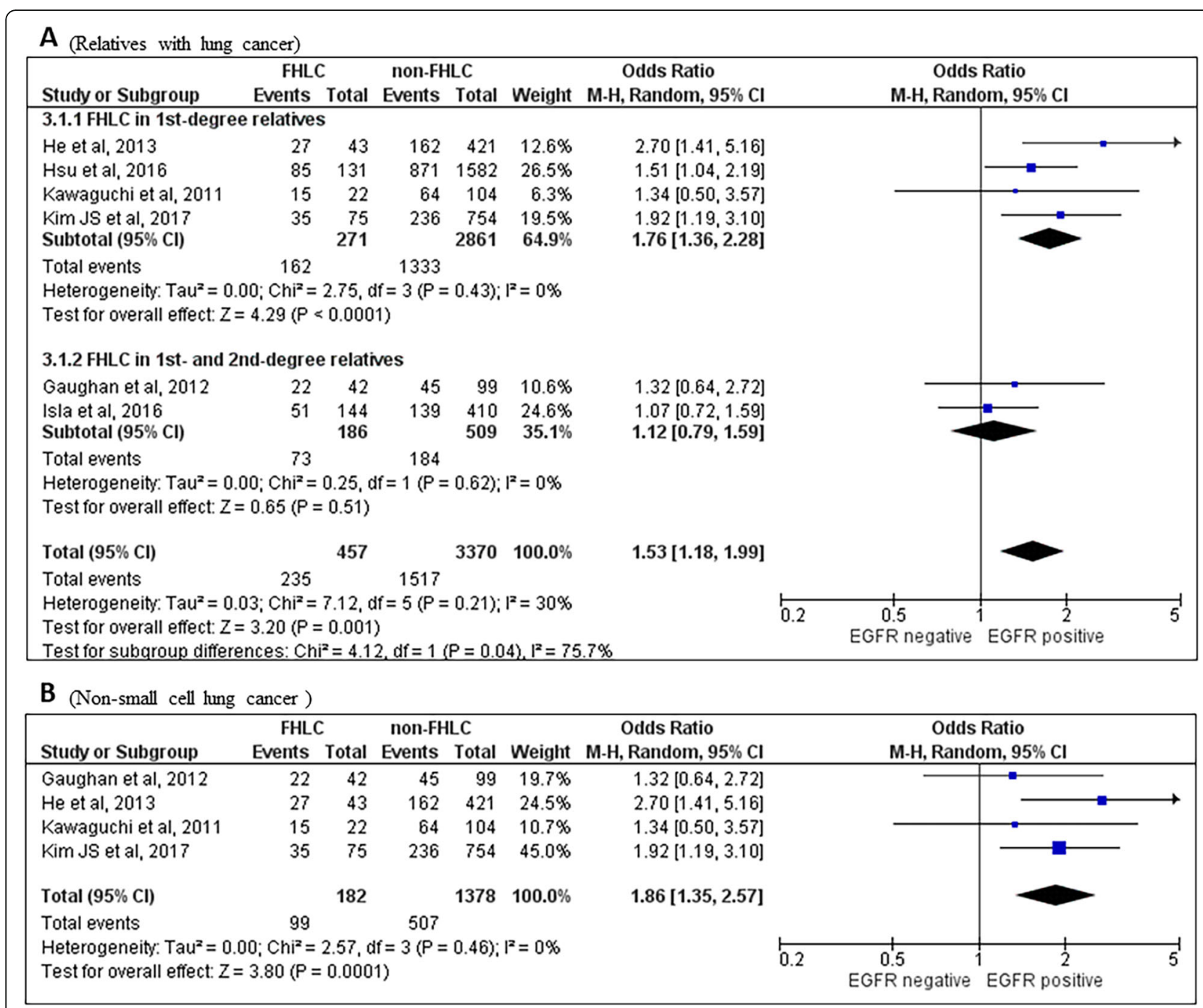

Fig. 3 Forest plots for family history of lung cancer and the risk of EGFR positive mutation. a Overall and according to relatives and $\mathbf{b}$ in nonsmall cell lung cancer patients. FHLC, family history of lung cancer; M-H, Mantel-Haenszel method; Cl, confidence interval

\section{Discussion}

Based on our study, a significant association between family history of malignancy and EGFR mutation in lung cancer has been observed in Asians, patients diagnosed as ADCs/NSCLCs or those with lung cancer-affected (first-degree) relatives. Individuals with family history of lung cancer among first-degree relatives have a high risk of lung cancer, bearing an OR ranging 1.51-1.63 after adjustment of other potential confounders [7, 8]; Asians have the highest risk compared to the White and Black/ African Americans (adjusted OR: 2.38, 1.46 and 1.67, respectively) [8]. Besides, somatic EGFR mutations occur more frequently in Asians, ADCs, females and neversmokers [20-22], a preferential subpopulation partly overlapping with that in our findings.

Family history is a substitute for inherited susceptibility. Recent studies have revealed some germline loci significantly contributing to the likelihood of EGFR mutation in lung cancer, e.g. 3q28 (rs7636839, TP63), 5p15.33 (re2736100 and rs2853677, TERT), 6p21 (rs2495239, FOXP4; rs3817963, BTNL2; rs2179920, HLA-DPB1), 6q22.2 (rs9387478, ROS1/DCBLD1) and 17q24.3 (rs7216064, BPTF) in Asians [62-64]. These findings suggest underlying genetic modifiers responsible for a predisposition to somatic EGFR mutation in lung cancer. Thus, it will be interesting to investigate the potential role of CPGs in the pathogenesis of somatic EGFR mutation in lung cancer.

We summarized the potential CPGs and mutated sites reported in familial lung cancers where somatic EGFR mutation status was available. Almost all the publications reported the predisposition genes by case-studying one or several lung cancer-clustering families. Some lung cancers complicated or fell within the spectrum of 


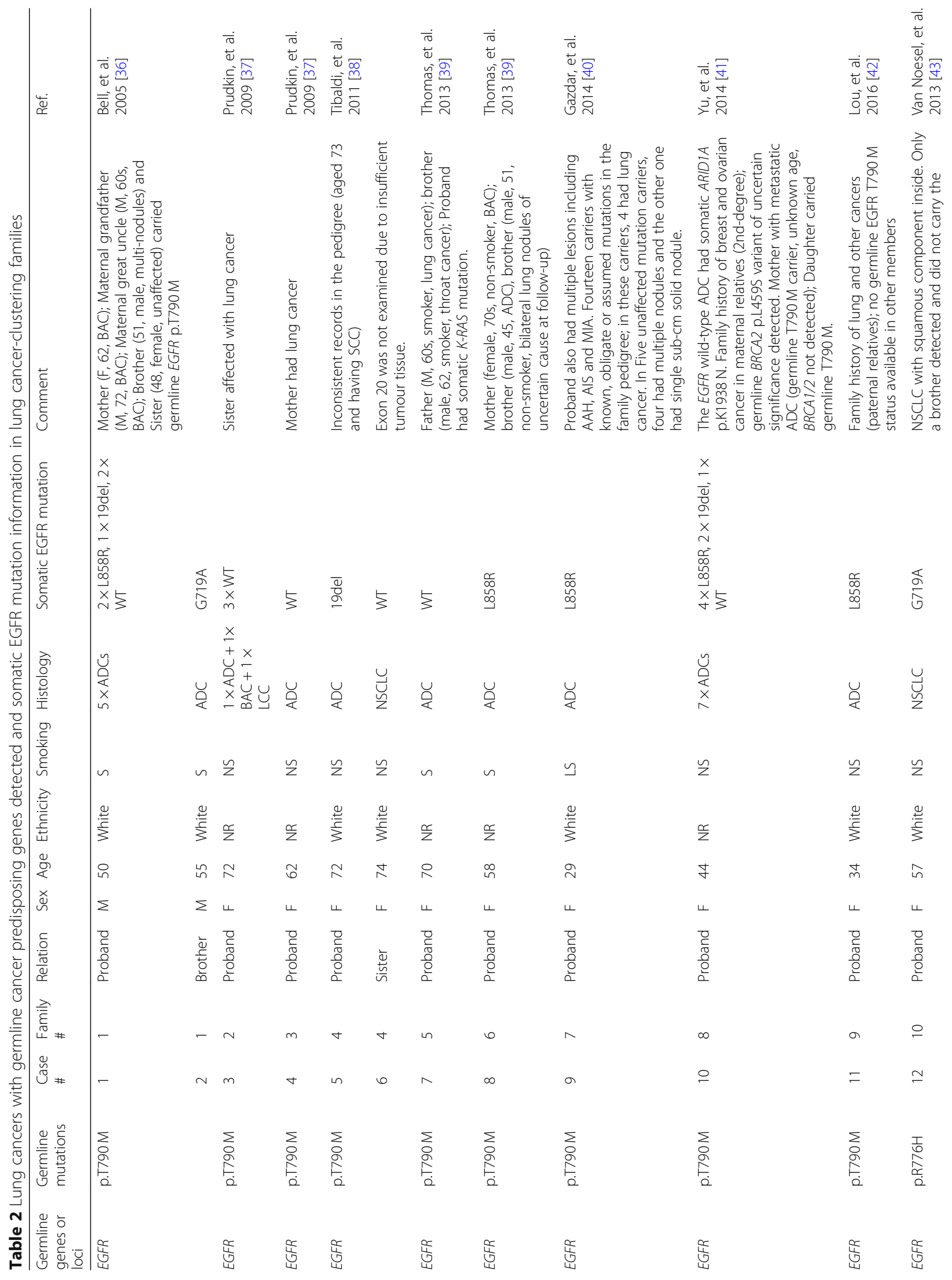




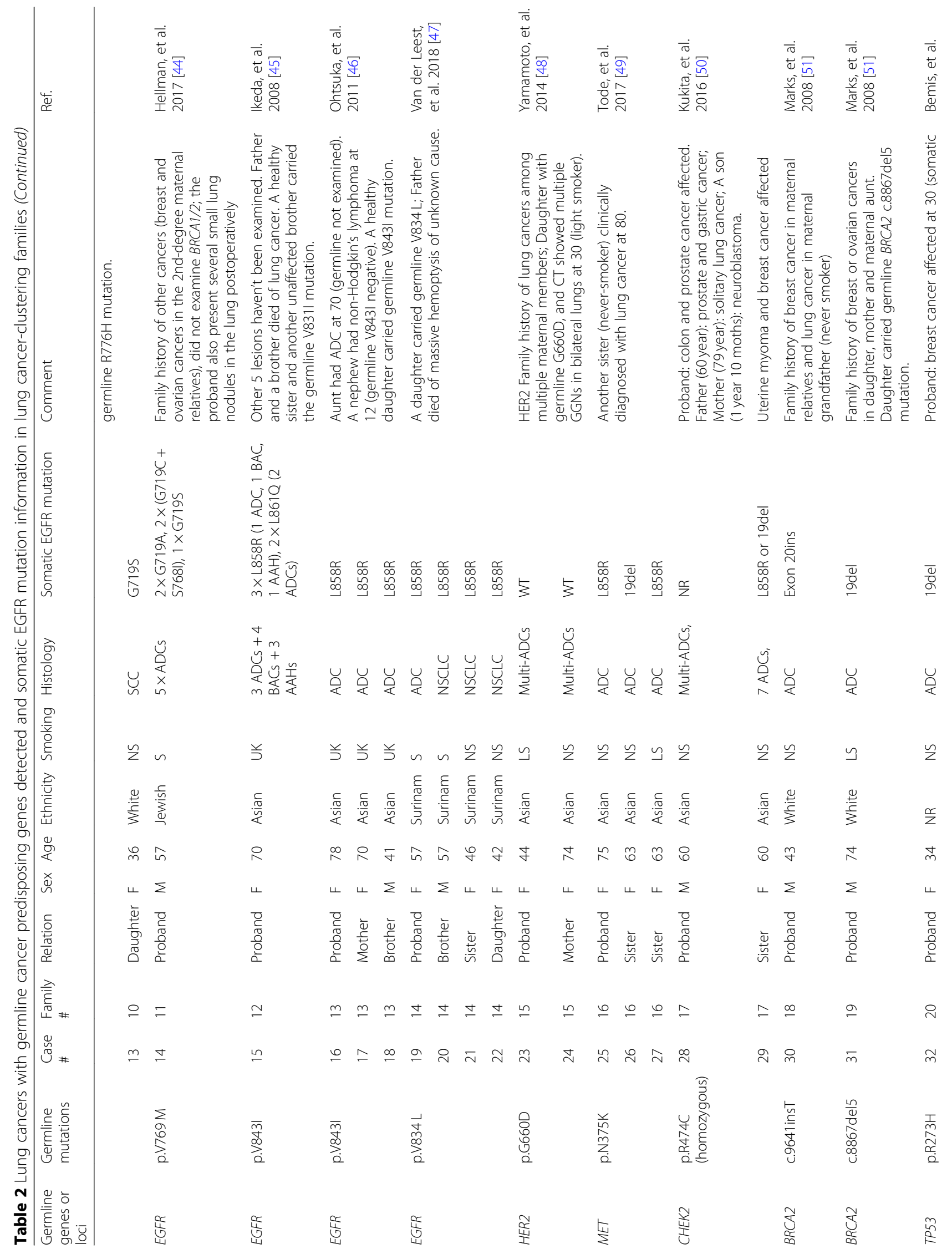




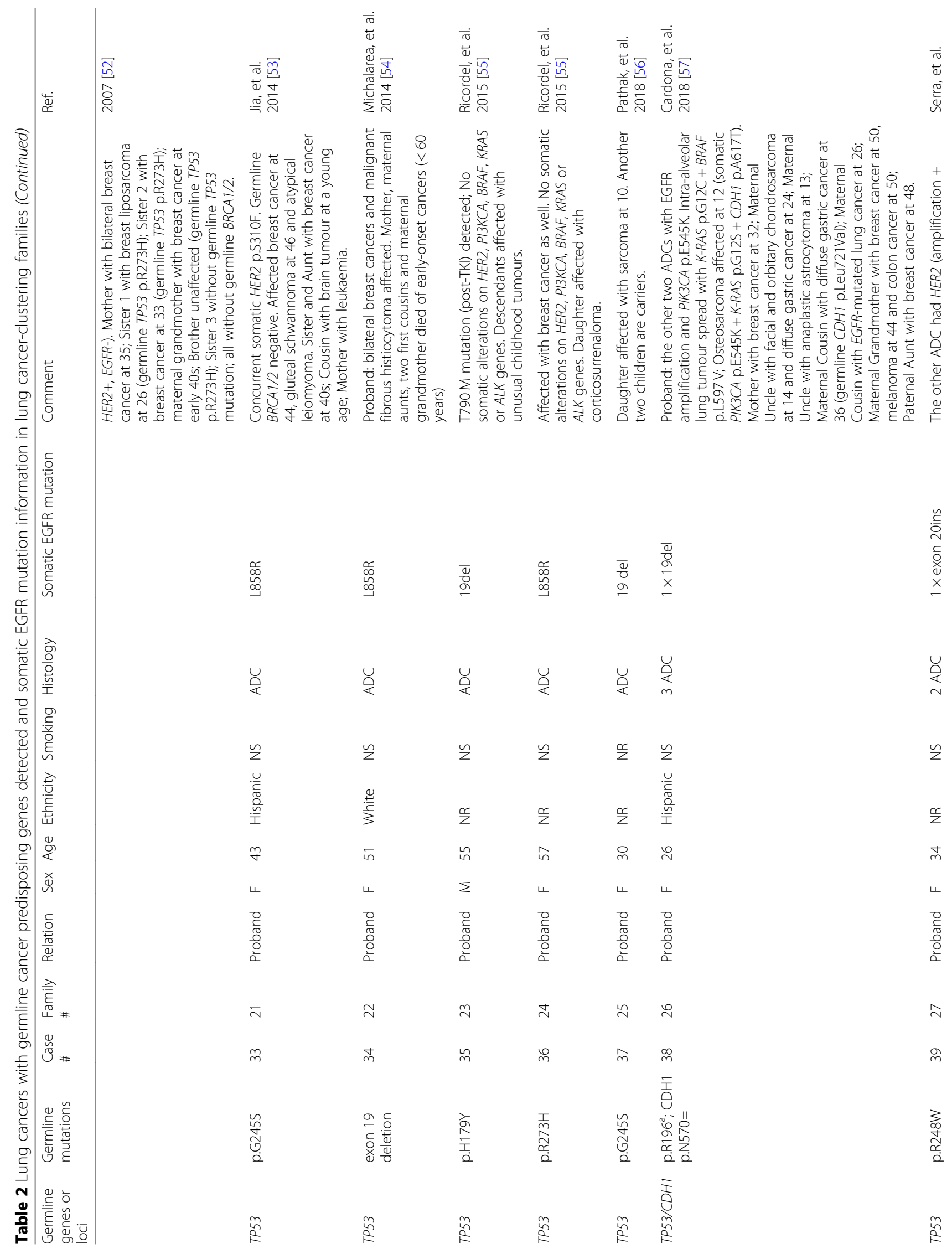


Cheng et al. BMC Cancer ～(2019) 19:1068

Page 11 of 17

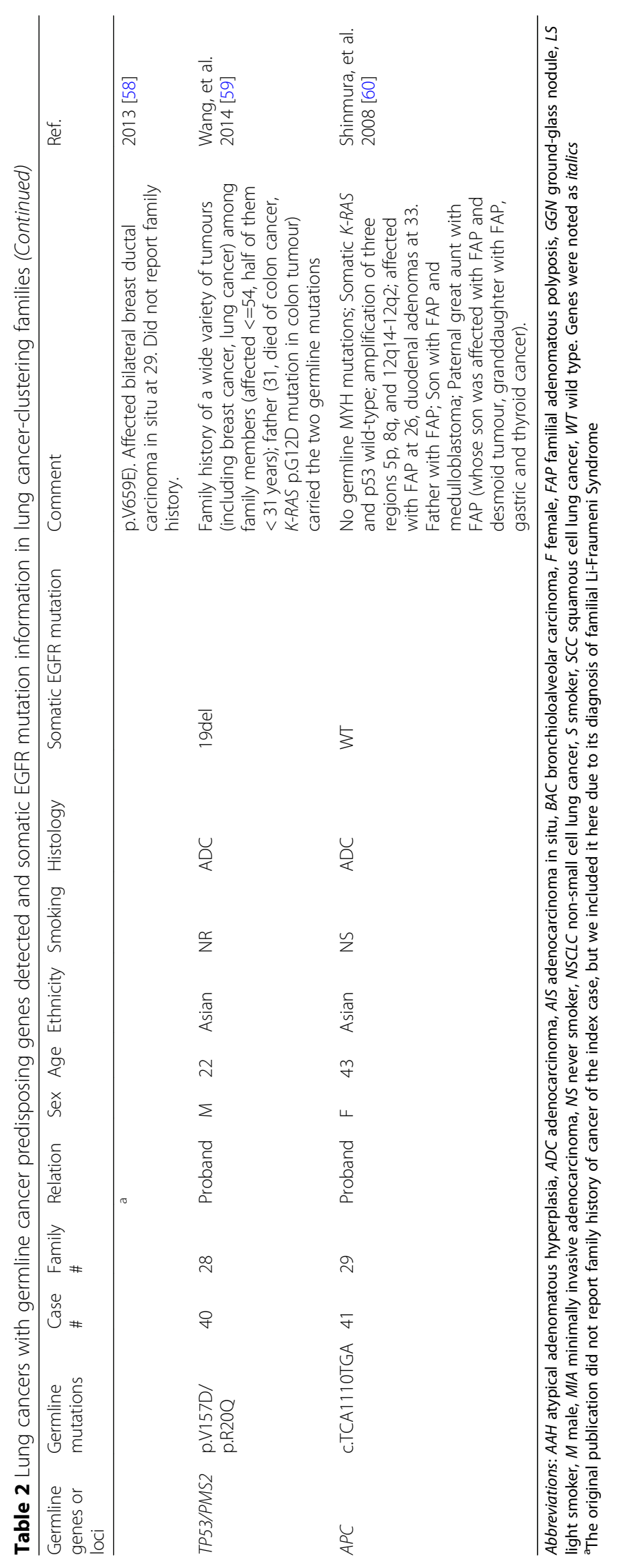


Table 3 Clinical characteristics of familial lung cancer cases curated in Table 2

\begin{tabular}{|c|c|c|}
\hline Characteristics & All & Germline EGFR carrier \\
\hline Case No. & 41 & 22 \\
\hline \multicolumn{3}{|l|}{ Age at diagnosis } \\
\hline Median (range) & $57(22-78)$ & $57(29-78)$ \\
\hline \multicolumn{3}{|l|}{ Gender } \\
\hline Male & $10(24.4 \%)$ & $5(22.7 \%)$ \\
\hline Female & $31(75.6 \%)$ & 17 (77.3\%) \\
\hline \multicolumn{3}{|l|}{ Smoking Status } \\
\hline Smoking ${ }^{a}$ & $11(26.8 \%)$ & $8(36.4 \%)$ \\
\hline Non-smoking & $24(58.5 \%)$ & $10(43.5 \%)$ \\
\hline Not reported & $6(14.6 \%)$ & $4(18.1 \%)$ \\
\hline Family No. & 29 & 14 \\
\hline Ethnicity & $29(100.0 \%)$ & $14(100.0 \%)$ \\
\hline White & $8(27.6 \%)$ & $5(35.7 \%)$ \\
\hline Asian & 7 (24.1\%) & $2(14.3 \%)$ \\
\hline Other & $4(13.8 \%)$ & $2(14.3 \%)$ \\
\hline Not reported & $10(34.5 \%)$ & $5(35.7 \%)$ \\
\hline Multiple lung tumours & $10(34.5 \%)$ & $6(42.9 \%)$ \\
\hline Lung tumour No. ${ }^{b}$ & $\geq 78$ & 47 \\
\hline \multicolumn{3}{|l|}{ Histology (by tumour) } \\
\hline Adenocarcinoma & $72(\sim 92.3 \%)$ & $41(87.2 \%)$ \\
\hline Other ${ }^{c}$ & $6(\sim 7.7 \%)$ & $6(12.8 \%)$ \\
\hline \multicolumn{3}{|c|}{ Somatic co-occurring EGFR mutation status } \\
\hline Mutated $^{d}$ & $54(69.2 \%)$ & $33(70.2 \%)$ \\
\hline L858R & $26(48.1 \%)$ & $19(57.6 \%)$ \\
\hline Exon 19del & $11(20.4 \%)$ & $4(8.5 \%)$ \\
\hline Other & $12(22.2 \%)$ & $10(30.3 \%)$ \\
\hline
\end{tabular}

Including both light smokers and smokers in Table 2

${ }^{b}$ Detailed number of lung tumours were not available in some cases diagnosed with "multiple lung cancers", thus we recorded their number as $\geq 2$ per case. The tumour number in Case \#9 in Family \#7 was recorded as one due to incomplete information regarding other pre-cancerous and pre-invasive lesions in the lung

'Including five non-small cell lung cancers and one squamous cell lung cancer ${ }^{\mathrm{d}}$ We recorded the mutated tumours in Case \#29 in Family \#17 as two (one L858R and the other 19del) due to no detailed information. Other mutations included G719C/S/A and exon 20 insertions

clinical manifestations of familial cancer syndromes. Though limited, the curated data may help to shed light on genetic mechanisms in modifying somatic alterations.

About a half of the families in our curated dataset have reported germline EGFR mutation among family members, mostly T790 M and in the White families. Germline EGFR mutations are very rare, less than 1/ $7500(0.01 \%)$ in the general population [40]; the proportion is higher in sporadic lung cancers, namely $1 /$ $555(0.18 \%)$ of lung ADCs from TCGA (mostly White) [65] and 14/12,833 (0.11\%) of Chinese lung cancers [66]. In two small datasets of familial cases lately, none of the patients has been detected as positive $[67,68]$.

As the most reported germline mutation, T790 M accounted for $1.0 \%$ (5/503) in EGFR-mutated lung cancers from the US. Comparably, the proportion of germline T790 M mutation was much lower in Asians, i.e. 0/ 627 in Japanese NSCLCs [40] and 1/12,833 in Chinese lung cancers [66], notwithstanding their substantially higher somatic EGFR mutation rate in the tumours. Therefore, there is inherited susceptibility difference across ethnicities, which may explain the potentially preferential distribution of cancer predisposition genes in our curated families.

Most of the cases with inherited EGFR mutation in our investigation had concurrent activating mutations in their tumours. Generally, the germline EGFR mutations reported could be oncogenic if alone [42-44, 46, 69]; and the growth potential would be enhanced dramatically when co-occurring with a secondary activating mutation [42-44, 46, 69], which may indicate a 'second-hit' proliferative advantage in the tumours $[42,70]$. Second somatic activating mutations non-randomly occurred in cis to the inherited mutations [36, 43, 46, 47]. Specifically, EGFR T790 M, the mutation responsible for over $50 \%$ of the acquired resistance post-TKI in EGFR-mutated lung cancers [61], emerges in cis with the initial drug-sensitizing EGFR mutation in the tumour as well [71]. T790 M has a modest oncogenic effect, which may be the explanation that it is tolerated in humans as a germline mutation [72]. In a cis configuration with the activating mutation, T790 M mutation could dramatically enhance EGFR catalytic activity, and thus, achieve a significant gain of function in transformation and tumour aggressiveness [36, 71, 72]. The increased proliferative advantage of the dual mutations has been observed in experimental conditions [73] as well as in clinical practice [74]. The evidence concerning the mechanisms of the mutual interactions between concurrent double mutations is limited. Presumably, the germline mutation carrier may more likely predispose to lung cancer or develop in a more aggressive nature following the subsequent second somatic mutation; and of note, it is not rare that these carriers have multiple apparently independent lung cancers or lung nodules, the later possibly associated with precancerous or pre-invasive lesions [40].

The distribution of secondary somatic mutations was not typically concordant across family members or multiple lung cancers in the same patient, similar to a previously reported small familial cohort [28]. However, there are some exceptions in our study. Familial cases with germline mutation V769 M had the somatic mutation at codon 719 [44]. Specifically, energy balance could be an explanation for the phenomenon: V769 M alone or with 
secondary mutations (except L858R) cost less energy to keep EGFR in the activated configuration than in the inactivated state, thus causing activation of EGFR [44]. For this reason, V769 M is more likely to combine with other mutations than L858R [44], which might be indirectly evidenced by the case reports from the COSMIC database where no concurrent V769 M and L858R mutations have been recorded yet [75]. The other three families, germline $\mathrm{R} 776 \mathrm{H}$ with a somatic mutation at codon 719 [43], and germline V834 L [47] and V843I [46] with somatic L858R among different family members, also caught our attention. However, in the records from COSMIC, no exclusive relations between these double mutations have been observed in the $\mathrm{R} 776 \mathrm{H}$, V834I or V843 L-mutated cases (but note that the origin of these mutations in COSMIC - somatic or germline - are mostly unknown and the sample size was small) [75]. Thus, coincidence could not be excluded here. Whether some other precise mechanisms are associated with the preferential combinations in dual/multiplex mutations, like energy balance, and how they function, have yet to be clarified.

Most of the remaining families had germline CPGs functioning in response to DNA damage or regulating DNA repair pathways, including BRCA2 [51], CHEK2 [50], TP53 [52-59] and PMS2 [59]. Carriers of these CPGs are vulnerable to familial cancers or inherited cancer syndromes, which could overlap with lung cancers, i.e. BRCA2 in hereditary breast/ovarian cancer [51], APC in familial adenomatous polyposis [60] and TP53 in LiFraumeni Syndrome [52-59]. Somatic EGFR mutations in these lung cancers are tentatively deletions or insertions (Table 2). Remarkably, these cases are affected with multiple-site lesions. In a recent analysis of germline sequencing data of 555 lung adenocarcinomas from TCGA, the authors found about $2.5 \%$ of the lung cases carried the germline mutations that could be linked to inherited risk [65]. Most of them are in DNA repair pathways, including ATM (7, 1.3\%), TP53 (4, 0.7\%) and BRCA2 (1, 0.18\%) [65], which are closely associated with familial cancer syndromes. What's more, individuals carrying these predisposing genes or cancer syndromes would have an increased risk of lung cancer [76-78].

Somatic driver mutations, including EGFR mutations, occur early in lung cancer evolution, and these earlyoccurring mutations tend to be histological-subtypespecific [79]. Generally, squamous-cell lung cancer harbours remarkably more clonal mutations (relating to early driver mutations) than lung adenocarcinoma due to differences in smoking behaviours. In never-smoker NSCLC females, somatic EGFR mutations are associated with increased exposure to environmental tobacco smoke [80]. Both active and passive smoking are exogenous insults and could result in genotoxic damage which can be enhanced when the endogenous DNA repair system is compromised. Thus, there may be a genetically definable subset of lung cancer patients harbouring germline mutations involved in the dysfunction of DNA repair system, where genomic instability may be a potential risk modifier for EGFR mutation in lung tumour.

$B R C A 1 / 2$, the genes responsible for double-strand break repairing, had a significantly lower expression due to its promoter hypermethylation in lung adenocarcinoma [81], potentially mediating genetic instability in lung tumorigenesis. Women with breast cancer have an increased risk of synchronous lung cancer (Hazard Ratio: 5.86 in ages 40-69) and vice versa [82]. Members in the hereditary branch of families of patients eligible for $B R C A$ test are at high risk of lung cancer, with an odds ratio of 4.5 compared to those belonging to the nonhereditary branch [78]. Twelve families in our curated dataset reported family or personal history of breast or ovarian cancer, five of which had germline $B R C A 1 / 2$ detected, and three probands had positive $B R C A 2$ germline mutations. All the three index cases were ADCs yet with somatic EGFR mutated in different codons. Some small subsets investigated the association between germline $B R C A 1 / 2$ mutation and EGFR-mutant lung cancer, but didn't have positive findings due to the rare frequency of the BRCA1/2 germline mutations [51].

Nine index patients with germline TP53 mutation in our dataset complexed with Li-Fraumeni Syndrome, which is associated with multiple, often rare, cancers. The nine index families presented early onset of cancer at multiple sites across the families, which was typically consistent with the clinical features of Li-Fraumeni Syndrome. The median age of the index patients was 34 years old at the diagnosis of lung cancer (range 22-57), and females (7/9) and never-smokers (7/9) predominated. One case had concurrent somatic EGFR activating mutation and HER2 point mutation [53]. Usually, these two driver mutations occur mutually exclusively [83]; but in this case may result from defective DNA repair due to TP53 mutation.

Somatically, HER2/ERBB2 is mutated in $2-4 \%$ of all NSCLCS, of which $80 \% \sim 100 \%$ are insertions in exon 20 [83]. Germline mutations in $H E R 2$ are also extremely rare: only one in 12,833 Chinese lung cancer patients has been identified by targeted next-generation sequencing. Yamamoto et al. reported the germline mutation HER2 G660D in the index family along with a germline HER2 V659 M mutation detected in a sporadic lung ADC [48]. Mutations on the transmembrane domain could favour kinase activation and $E R B B 2$ dimerization thus stimulating the $M E K /$ ERK signalling [84]. Both G660D and V659E are located at the transmembrane domain. Their mutant proteins are more stable than the wild-type and possess an oncogenic potential by activating $A k t$ and $p 38$, thus facilitating cell 
growth and survival [48]. MET and EGFR are mutual complements, which activate the PISK-AKT pathway by interacting with ERBB3; therefore, the inactivation of $M E T$ by its heterozygous germline mutation could complementarily enhance the EGFR-ERBB3-PI3K axis [49]. The oncogenic stress may explain the pathogenesis of EGFR mutation in lung cancer [49].

Despite the evidence presented, we should bear in mind is that cases available for the current study (both the meta-analysis and the following dataset curation) are very limited. Caution is warranted in the data interpretation. Moreover, lung cancer is multifactorial and the genetics basis is complex. Current research on cancer predisposing genes is usually based on assumptions, which would over-extrapolate the data [16]. Many susceptibility genes may only explain a small portion of the inherited susceptibility; but these genes with small or moderate effects might, in combination, act additively or synergistically to result in lung cancer susceptibility. The acquisition of specific somatic mutations in a background of predisposing genes may drive cancer evolution in a particular direction. Which genes behave this way and how the genetic aberrations function during lung cancer evolution are still undetermined.

Regarding the current study, other drawbacks besides data limitation include: 1) recall bias and selective reporting bias due to retrospective study designs; 2) mostly Asian patients, which are possibly not representative of other ethnicities; 3) heterogeneity in detection methods [85]; 4) intra-tumour heterogeneity (one single diagnostic assessment may not represent the whole picture) [79]; 5) differences in definitions regarding EGFR positive mutation (however, we presume the conclusion would not be significantly changed, since L858R and $19 \mathrm{del}$ are the most frequently mutated in lung cancer and other mutations reported in the studies we pooled here are limited); 6) heterogeneity in study populations (subgroup analysis in the current meta-analysis may help); 7) bias resulting from self-reported family history (However, this may not be a major issue, since there is a high positive predictive value and sensitivity in it by a recent systematic review [86]).

\section{Conclusions}

Given current evidence and our observations, there are potentially different genetic modifiers in somatically $E G F R$-mutant lung cancers from their wild-type counterparts. Familial lung cancers tentatively favour adenocarcinoma, females, never-smokers, coexistence with secondary somatic EGFR mutation and occasionally multi-focal lesions. Among them, germline EGFR mutation carriers affected with lung cancers are more frequently the White ethnicity. Some mechanisms such as energy balance may attribute to the specific secondary
EGFR mutation type in the tumour of familial cases. However, caution needs to be taken when interpreting the data, as it is incomplete. Further studies on this topic should be encouraged, which will hopefully provide a more detailed genetic landscape for lung cancer aetiology.

\section{Supplementary information}

Supplementary information accompanies this paper at https://doi.org/10. 1186/s12885-019-6317-6.

Additional file 1: Table S1. Searching strategies for the meta-analysis. Table S2. Searching strategies for the second literature review. Table S3. Evaluation of case-control study quality with The Newcastle-Ottawa Scale (NOS) in meta-analyses. Table S4. Evaluation of cohort study quality with The Newcastle-Ottawa Scale (NOS) in meta-analyses. Figure S1. Forest plot of family history of any cancer and the risk of EGFR positive mutation (11 studies included). Figure S2. Funnel plot of family history of cancer and the risk of somatic EGFR positive mutation in lung cancer.

\section{Abbreviations}

ADC: Adenocarcinoma; CPG: Cancer predisposition gene; EGFR: Epidermal growth factor receptor; FH_All: Family history of all cancers; FH_Any: Family history of any cancer; FH_Other: Family history of other cancer except lung cancer; FHLC: Family history of lung cancer; NSCLC: Non-small cell lung cancer; OR: Odds ratio; TKl: Tyrosine kinase inhibitor

\section{Acknowledgements}

Not applicable.

\section{Authors' contributions}

Conception development and article design: WML, YIC and YCG. Database research, curation and analysis: YIC and YCG. Manuscript writing: YIC and YCG. Substantial manuscript revision: DL, MPAD and JKF. All the authors approved the final manuscript.

\section{Funding}

YIC is funded by China Scholarship Council (CSC201706240094) and West China-Liverpool Clinician-Scientist Leadership Scholarship. MPAD is funded by the Roy Castle Lung Cancer Foundation. This work is also partly supported by the 1.3.5 Project for Disciplines of Excellence, West China Hospital, Sichuan University (ZYJC18001), the National Key Development Plan for Precision Medicine Research (2017YFC0910004) and the Transformation Projects of Sci-Tech Achievements of Sichuan Province (2016CZYD0001). The funding bodies had no influences on the design of the study and collection, analysis, and interpretation of data and in writing the manuscript.

\section{Availability of data and materials}

All data generated or analysed during this study are included in this published article and its supplemental information files.

\section{Ethics approval and consent to participate}

Ethical approval and consent had been obtained in the original studies. They were not required in the current study because it was a secondary anonymised analysis of the original publications.

\section{Consent for publication}

No consent for publication was required due to curation of data from published papers.

\section{Competing interests}

The authors declare that they have no competing interests.

\section{Author details}

${ }^{1}$ Department of Respiratory and Critical Care Medicine, West China Hospital, Sichuan University, Chengdu 610041, China. ${ }^{2}$ Lung Cancer Research Group, Department of Molecular and Clinical Cancer Medicine, Institute of 
Translational Medicine, University of Liverpool, William Henry Duncan Building, 6 West Derby Street, Liverpool L7 8TX, UK.

\section{Received: 6 March 2019 Accepted: 31 October 2019 Published online: 08 November 2019}

\section{References}

1. Bray F, Ferlay J, Soerjomataram I, Siegel RL, Torre LA, Jemal A. Global cancer statistics 2018: GLOBOCAN estimates of incidence and mortality worldwide for 36 cancers in 185 countries. CA Cancer J Clin. 2018;68(6):394-424.

2. Islami F, Goding Sauer A, Miller KD, Siegel RL, Fedewa SA, Jacobs EJ, et al. Proportion and number of cancer cases and deaths attributable to potentially modifiable risk factors in the United States. CA Cancer J Clin. 2018;68(1):31-54.

3. Parkin DM. 2. Tobacco-attributable cancer burden in the UK in 2010. Br J Cancer. 2011;105(Suppl 2):S6-S13.

4. Islami F, Chen W, Yu XQ, Lortet-Tieulent J, Zheng R, Flanders WD, et al. Cancer deaths and cases attributable to lifestyle factors and infections in China, 2013. Ann Oncol. 2017;28(10):2567-74.

5. Matakidou A, Eisen T, Houlston RS. Systematic review of the relationship between family history and lung cancer risk. Br J Cancer. 2005;93(7):825-33.

6. Gu J, Hua F, Zhong D, Chen J, Liu H, Zhou Q. Systematic review of the relationship between family history of lung cancer and lung cancer risk. Zhongguo Fei Ai Za Zhi. 2010;13(3):224-9.

7. Lissowska J, Foretova L, Dabek J, Zaridze D, Szeszenia-Dabrowska N, Rudnai $P$, et al. Family history and lung cancer risk: international multicentre casecontrol study in eastern and Central Europe and meta-analyses. Cancer Causes Control. 2010;21(7):1091-104.

8. Cote ML, Liu M, Bonassi S, Neri M, Schwartz AG, Christiani DC, et al. Increased risk of lung cancer in individuals with a family history of the disease: a pooled analysis from the international lung Cancer consortium. Eur J Cancer. 2012;48(13):1957-68.

9. $\quad$ Lin $\mathrm{H}$, Huang YS, Yan HH, Yang XN, Zhong WZ, Ye HW, et al. A family history of cancer and lung cancer risk in never-smokers: a clinic-based casecontrol study. Lung Cancer. 2015;89(2):94-8.

10. Yu H, Frank C, Hemminki A, Sundquist K, Hemminki K. Other cancers in lung cancer families are overwhelmingly smoking-related cancers. ERJ Open Res. 2017;3(2):00006-2017.

11. Li Y, Xiao X, Han Y, Gorlova O, Qian D, Leighl N, et al. Genome-wide interaction study of smoking behavior and non-small cell lung cancer risk in Caucasian population. Carcinogenesis. 2018;39(3):336-46.

12. Yu YW, Wang CP, Han YF, Niu JJ, Zhang YZ, Fang Y. Meta-analysis on related risk factors regarding lung cancer in non-smoking Chinese women. Zhonghua Liu Xing Bing Xue Za Zhi. 2016;37(2):268-72.

13. Galvan A, Falvella FS, Frullanti E, Spinola M, Incarbone M, Nosotti M, et al. Genome-wide association study in discordant sibships identifies multiple inherited susceptibility alleles linked to lung cancer. Carcinogenesis. 2010; 31(3):462-5.

14. Li Y, Sheu C-C, Ye Y, de Andrade M, Wang L, Chang S-C, et al. Genetic variants and risk of lung cancer in never smokers: a genome-wide association study. Lancet Oncol. 2010;11(4):321-30.

15. Machiela MJ, Hsiung CA, Shu XO, Seow WJ, Wang Z, Matsuo K, et al. Genetic variants associated with longer telomere length are associated with increased lung cancer risk among never-smoking women in Asia: a report from the female lung cancer consortium in Asia. Int J Cancer. 2015;137(2):311-9.

16. Rahman N. Realizing the promise of cancer predisposition genes. Nature. 2014;505(7483):302-8.

17. Park S, Supek F, Lehner B. Systematic discovery of germline cancer predisposition genes through the identification of somatic second hits. Nat Commun. 2018;9(1):2601.

18. Castellanos E, Feld E, Horn L. Driven by mutations: the predictive value of mutation subtype in EGFR-mutated non-small cell lung Cancer. J Thorac Oncol. 2017;12(4):612-23.

19. Dearden S, Stevens J, Wu YL, Blowers D. Mutation incidence and coincidence in non small-cell lung cancer: meta-analyses by ethnicity and histology (mutMap). Ann Oncol. 2013;24(9):2371-6.

20. Gou LY, Niu FY, Wu YL, Zhong WZ. Differences in driver genes between smoking-related and non-smoking-related lung cancer in the Chinese population. Cancer. 2015;121(Suppl 17):3069-79.
21. El-Telbany A, Ma PC. Cancer genes in lung cancer: racial disparities: are there any? Genes Cancer. 2012:3(7-8):467-80.

22. Shigematsu H, Lin L, Takahashi T, Nomura M, Suzuki M, Wistuba II, et al. Clinical and biological features associated with epidermal growth factor receptor gene mutations in lung cancers. J Natl Cancer Inst. 2005:97(5):339-46.

23. Stroup DF, Berlin JA, Morton SC, Olkin I, Williamson GD, Rennie D, et al. Meta-analysis of observational studies in epidemiology: a proposal for reporting. Meta-analysis of observational studies in epidemiology (MOOSE) group. JAMA. 2000;283(15):2008-12.

24. Higgins J.P.T, Green S (editors). Cochrane Handbook for Systematic Reviews of Interventions Version 5.1.0 [updated March 2011]. The Cochrane Collaboration, 2011. https://www.handbook.cochrane.org Accessed on date 25 Jul 2019.

25. Cheng PC, Cheng YC. Correlation between familial cancer history and epidermal growth factor receptor mutations in Taiwanese never smokers with non-small cell lung cancer: a case-control study. J Thorac Dis. 2015;7(3):281-7.

26. Gaughan EM, Cryer SK, Yeap BY, Jackman DM, Costa DB. Family history of lung cancer in never smokers with non-small-cell lung cancer and its association with tumors harboring EGFR mutations. Lung Cancer. 2013;79(3):193-7.

27. He YY, Li S, Ren SX, Cai WJ, Li XF, Zhao C, et al. Impact of family history of cancer on the incidence of mutation in epidermal growth factor receptor gene in non-small cell lung cancer patients. Lung Cancer. 2013;81(2):162-6.

28. Hsu KH, Tseng JS, Wang CL, Yang TY, Tseng CH, Chen HY, et al. Higher frequency but random distribution of EGFR mutation subtypes in familial lung cancer patients. Oncotarget. 2016;7(33):53299-308.

29. Isla D, Felip E, Vinolas N, Provencio M, Majem M, Artal A, et al. Lung Cancer in women with a family history of Cancer: the Spanish female-specific database WORLD07. Anticancer Res. 2016;36(12):6647-53.

30. Kawaguchi T, Ando M, Kubo A, Takada M, Atagi S, Okishio K, et al. Long exposure of environmental tobacco smoke associated with activating EGFR mutations in never-smokers with non-small cell lung Cancer. Clin Cancer Res. 2011;17(1):39-45.

31. Kim JS, Cho MS, Nam JH, Kim HJ, Choi KW, Ryu JS. Prognostic impact of EGFR mutation in non-small-cell lung cancer patients with family history of lung cancer. PLoS One. 2017:12(5):e0177015.

32. Kim SY, Kim HR, Kim CH, Koh JS, Baek HJ, Choi CM, et al. Association between thyroid cancer and epidermal growth factor receptor mutation in female with nonsmall cell lung cancer. Ann Thorac Med. 2017;12(1):36-41.

33. Okudela K, Woo T, Yazawa T, Ogawa N, Tajiri M, Masuda M, et al. Significant association between EGFR-mutated lung adenocarcinoma and past illness from gastric cancer or uterine myoma: its implication in carcinogenesis. Lung Cancer. 2009;66(3):287-91.

34. Wang CD, Wang XR, Wang CY, Tang YJ, Hao MW. Relevance of EGFR gene mutation with pathological features and prognosis in patients with nonsmall-cell lung carcinoma. Asian Pac J Trop Med. 2015;8(3):249-52.

35. Zhu J, Cai L, Yang H, Wen Y, Wang J, Rong T, et al. Echinoderm microtubule-associated protein-like 4-anaplastic lymphoma kinase rearrangement and epidermal growth factor receptor mutation coexisting in Chinese patients with lung adenocarcinoma. Thorac Cancer. 2014:5(5):411-6.

36. Bell DW, Gore I, Okimoto RA, Godin-Heymann N, Sordella R, Mulloy R, et al. Inherited susceptibility to lung cancer may be associated with the T790M drug resistance mutation in EGFR. Nat Genet. 2005;37(12):1315-6.

37. Prudkin L, Tang X, Wistuba II. Germ-line and somatic presentations of the EGFR T790M mutation in lung cancer. J Thorac Oncol. 2009;4(1):139-41.

38. Tibaldi C, Giovannetti E, Vasile E, Boldrini L, Gallegos-Ruiz MI, Bernardini I, et al. Inherited germline T790M mutation and somatic epidermal growth factor receptor mutations in non-small cell lung cancer patients. J Thorac Oncol. 2011:6(2):395-6.

39. Thomas A, Xi L, Carter CA, Rajan A, Khozin S, Szabo E, et al. Concurrent molecular alterations in tumors with germ line epidermal growth factor receptor T790M mutations. Clin Lung Cancer. 2013;14(4):452-6.

40. Gazdar A, Robinson L, Oliver D, Xing C, Travis WD, Soh J, et al. Hereditary lung cancer syndrome targets never smokers with germline EGFR gene T790M mutations. J Thorac Oncol. 2014;9(4):456-63.

41. Yu HA, Arcila ME, Harlan Fleischut M, Stadler Z, Ladanyi M, Berger MF, et al. Germline EGFR T790M mutation found in multiple members of a familial cohort. J Thorac Oncol. 2014;9(4):554-8. 
42. Lou Y, Pecot CV, Tran HT, DeVito VJ, Tang XM, Heymach JV, et al. Germline mutation of T790M and dual/multiple EGFR mutations in patients with lung adenocarcinoma. Clin Lung Cancer. 2016;17(2):e5-11.

43. van Noesel J, van der Ven WH, van Os TA, Kunst PW, Weegenaar J, Reinten $\mathrm{RJ}$, et al. Activating germline $\mathrm{R} 776 \mathrm{H}$ mutation in the epidermal growth factor receptor associated with lung cancer with squamous differentiation. J Clin Oncol. 2013;31(10):e161-4.

44. Hellmann MD, Hayashi T, Reva B, Yu HA, Riely GJ, Adusumilli PS, et al. Identification and functional characterization of EGFR V769M, a novel Germline variant associated with multiple lung adenocarcinomas. JCO Precision Oncology. 2017;1:1-10.

45. Ikeda K, Nomori H, Mori T, Sasaki J, Kobayashi T. Novel germline mutation: EGFR V843I in patient with multiple lung adenocarcinomas and family members with lung cancer. Ann Thorac Surg. 2008;85(4):1430-2.

46. Ohtsuka K, Ohnishi H, Kurai D, Matsushima S, Morishita Y, Shinonaga M, et al. Familial lung adenocarcinoma caused by the EGFR V843I germ-line mutation. J Clin Oncol. 2011;29(8):e191-2.

47. van der Leest C, Wagner A, Pedrosa RM, Aerts JG, Dinjens WNM, Dubbink HJ. Novel EGFR V834L Germline mutation associated with familial lung adenocarcinoma. JCO Precision Oncology. 2018;2:1-5.

48. Yamamoto H, Higasa K, Sakaguchi M, Shien K, Soh J, Ichimura K, et al. Novel germline mutation in the transmembrane domain of HER2 in familial lung adenocarcinomas. J Natl Cancer Inst. 2014;106(1):djt338.

49. Tode N, Kikuchi T, Sakakibara T, Hirano T, Inoue A, Ohkouchi S, et al. Exome sequencing deciphers a germline MET mutation in familial epidermal growth factor receptor-mutant lung cancer. Cancer Sci. 2017;108(6):1263-70.

50. Kukita Y, Okami J, Yoneda-Kato N, Nakamae I, Kawabata T, Higashiyama M, et al. Homozygous inactivation of CHEK2 is linked to a familial case of multiple primary lung cancer with accompanying cancers in other organs. Cold Spring Harb Mol Case Stud. 2016;2(6):a001032.

51. Marks JL, Golas B, Kirchoff T, Miller VA, Riely GJ, Offit K, et al. EGFR mutant lung adenocarcinomas in patients with germline BRCA mutations. J Thorac Oncol. 2008;3(7):805.

52. Bemis LT, Robinson WA, McFarlane R, Buyers E, Kelly K, Varella-Garcia M, et al. EGFR-mutant lung adenocarcinoma in a patient with Li-Fraumeni syndrome. Lancet Oncol. 2007;8(6):559-60.

53. Jia Y, Ali SM, Saad S, Chan CA, Miller VA, Halmos B. Successful treatment of a patient with Li-Fraumeni syndrome and metastatic lung adenocarcinoma harboring synchronous EGFR L858R and ERBB2 extracellular domain S310F mutations with the pan-HER inhibitor afatinib. Cancer Biol Ther. 2014;15(8):970-4.

54. Michalarea V, Calcasola M, Cane P, Tobal K, Izatt L, Spicer J. EGFR-mutated lung cancer in Li-Fraumeni syndrome. Lung Cancer. 2014;85(3):458-87.

55. Ricordel C, Labalette-Tiercin M, Lespagnol A, Kerjouan M, Dugast C, Mosser J, et al. EFGR-mutant lung adenocarcinoma and Li-Fraumeni syndrome: report of two cases and review of the literature. Lung Cancer. 2015;87(1):80-4.

56. Pathak S, Singh SRK, Katiyar V, McDunn S. Epidermal growth factor receptormutated lung Cancer as the initial manifestation of Germline TP53 mutation associated Cancer. Cureus. 2018;10(3):e2395.

57. Cardona AF, Zatarain-Barron ZL, Rubio C, Martinez S, Ruiz-Patino A, Ricaurte $L$, et al. Probable hereditary familial overlap syndrome with multiple synchronous lung tumors. Lung Cancer. 2018;124:279-82.

58. Serra V, Vivancos A, Puente XS, Felip E, Silberschmidt D, Caratu G, et al. Clinical response to a lapatinib-based therapy for a Li-Fraumeni syndrome patient with a novel HER2V659E mutation. Cancer Discov. 2013;3(11):1238-44

59. Wang Z, Sun Y, Gao B, Lu Y, Fang R, Gao Y, et al. Two co-existing germline mutations P53 V157D and PMS2 R20Q promote tumorigenesis in a familial cancer syndrome. Cancer Lett. 2014;342(1):36-42.

60. Shinmura K, Suzuki M, Yamada H, Tao H, Goto M, Kamo T, et al. Characterization of adenocarcinoma of the lung in a familial adenomatous polyposis patient. Pathol Int. 2008;58(11):706-12.

61. Lovly C, Horn L, Oxnard G, Pao W. EGFR c.2369C>T (T790M) Mutation in Non-Small Cell Lung Cancer. My Cancer Genome 2016 [https://www. mycancergenome.org/content/disease/lung-cancer/egfr/4/] (Updated November 11).

62. Seow WJ, Matsuo K, Hsiung CA, Shiraishi K, Song M, Kim HN, et al. Association between GWAS-identified lung adenocarcinoma susceptibility loci and EGFR mutations in never-smoking Asian women, and comparison with findings from Western populations. Hum Mol Genet. 2017;26(2):454-65.
63. Wei R, Cao L, Pu H, Wang H, Zheng Y, Niu X, et al. TERT polymorphism rs2736100-C is associated with EGFR mutation-positive non-small cell lung Cancer. Clin Cancer Res. 2015;21(22):5173-80.

64. Shiraishi K, Okada Y, Takahashi A, Kamatani Y, Momozawa Y, Ashikawa K, et al. Association of variations in HLA class II and other loci with susceptibility to EGFR-mutated lung adenocarcinoma. Nat Commun. 2016;7:12451.

65. Parry EM, Gable DL, Stanley SE, Khalil SE, Antonescu V, Florea L, et al. Germline mutations in DNA repair genes in lung adenocarcinoma. J Thorac Oncol. 2017;12(11):1673-8.

66. Lu S, Yu Y, Li Z, Yu R, Wu X, Bao H, et al. Brief report: EGFR and ERBB2 Germline mutations in Chinese lung Cancer patients and their roles in genetic susceptibility to Cancer. J Thorac Oncol. 2019;14(4):732-6.

67. Centeno I, Blay P, Santamaria I, Astudillo A, Pitiot AS, Osorio FG, et al. Germline mutations in epidermal growth factor receptor (EGFR) are rare but may contribute to oncogenesis: a novel germ-line mutation in EGFR detected in a patient with lung adenocarcinoma. BMC Cancer. 2011;11:172.

68. Vikis $H$, Sato M, James M, Wang D, Wang Y, Wang M, et al. EGFR-T790M is a rare lung cancer susceptibility allele with enhanced kinase activity. Cancer Res. 2007;67(10):4665-70.

69. Oxnard GR, Arcila ME, Chmielecki J, Ladanyi M, Miller VA, Pao W. New strategies in overcoming acquired resistance to epidermal growth factor receptor tyrosine kinase inhibitors in lung cancer. Clin Cancer Res. 2011; 17(17):5530-7.

70. Yokoyama T, Kondo M, Goto Y, Fukui T, Yoshioka H, Yokoi K, et al. EGFR point mutation in non-small cell lung cancer is occasionally accompanied by a second mutation or amplification. Cancer Sci. 2006;97(8):753-9.

71. Hidaka N, Iwama E, Kubo N, Harada T, Miyawaki K, Tanaka K, et al. Most T790M mutations are present on the same EGFR allele as activating mutations in patients with non-small cell lung cancer. Lung Cancer. 2017; 108:75-82.

72. Godin-Heymann N, Bryant I, Rivera MN, Ulkus L, Bell DW, Riese DJ 2nd, et al. Oncogenic activity of epidermal growth factor receptor kinase mutant alleles is enhanced by the T790M drug resistance mutation. Cancer Res. 2007;67(15):7319-26.

73. Regales L, Balak MN, Gong Y, Politi K, Sawai A, Le C, et al. Development of new mouse lung tumor models expressing EGFR T790M mutants associated with clinical resistance to kinase inhibitors. PLoS One. 2007;2(8):e810.

74. Oxnard GR, Miller VA, Robson ME, Azzoli CG, Pao W, Ladanyi M, et al. Screening for germline EGFR T790M mutations through lung cancer genotyping. J Thorac Oncol. 2012;7(6):1049-52.

75. Catalogue Of Somatic Mutations In Cancer [https://cancer.sanger.ac.uk/ cosmic] Accessed on date 25 Jul 2019.

76. Swift M, Morrell D, Massey RB, Chase CL. Incidence of cancer in 161 families affected by ataxia-telangiectasia. N Engl J Med. 1991;325(26):1831-6.

77. Hwang SJ, Cheng LS, Lozano G, Amos Cl, Gu X, Strong LC. Lung cancer risk in germline p53 mutation carriers: association between an inherited cancer predisposition, cigarette smoking, and cancer risk. Hum Genet. 2003;113(3):238-43.

78. Digennaro M, Sambiasi D, Tommasi S, Pilato B, Diotaiuti S, Kardhashi A, et al Hereditary and non-hereditary branches of family eligible for BRCA test: cancers in other sites. Hered Cancer Clin Pract. 2017;15:7.

79. Jamal-Hanjani M, Wilson GA, McGranahan N, Birkbak NJ, Watkins TBK, Veeriah $\mathrm{S}$, et al. Tracking the evolution of non-small-cell lung Cancer. N Engl J Med. 2017;376(22):2109-21.

80. Soo RA, Kubo A, Ando M, Kawaguchi T, Ahn MJ, Ou SI. Association between environmental tobacco smoke exposure and the occurrence of EGFR mutations and ALK rearrangements in never-smokers with non-small-cell lung Cancer: analyses from a prospective multinational ETS registry. Clin Lung Cancer. 2017;18(5):535-42.

81. Lee MN, Tseng RC, Hsu HS, Chen JY, Tzao C, Ho WL, et al. Epigenetic inactivation of the chromosomal stability control genes BRCA1, BRCA2, and XRCC5 in non-small cell lung cancer. Clin Cancer Res. 2007;13(3):832-8.

82. Lin EP, Lin CH, Yang CY, Lu TP, Chang SN, Hsiao TH, et al. Population-based cohort study reveals distinct associations between female lung Cancer and breast Cancer in Taiwan. JCO Clin Cancer Inform. 2018;2:1-14.

83. Lovly C, Horn L, Gautschi O, Pao W. HER2 (ERBB2) Exon 20 Insertion in Non-Small Cell Lung Cancer. My Cancer Genome 2015 [https:// www.mycancergenome.org/content/disease/lung-cancer/erbb2/65/] (Updated June 18)

84. Yamamoto H, Toyooka S, Ninomiya T, Matsumoto S, Kanai M, Tomida S, et al. Therapeutic potential of Afatinib for cancers with ERBB2 (HER2) 
Transmembrane domain mutations G660D and V659E. Oncologist. 2018; 23(2):150-4.

85. Roengvoraphoj M, Tsongalis GJ, Dragnev KH, Rigas JR. Epidermal growth factor receptor tyrosine kinase inhibitors as initial therapy for non-small cell lung cancer: focus on epidermal growth factor receptor mutation testing and mutation-positive patients. Cancer Treat Rev. 2013;39(8):839-50.

86. Fiederling J, Shams AZ, Haug U. Validity of self-reported family history of cancer: a systematic literature review on selected cancers. Int I Cancer. 2016;139(7):1449-60

\section{Publisher's Note}

Springer Nature remains neutral with regard to jurisdictional claims in published maps and institutional affiliations.

Ready to submit your research? Choose BMC and benefit from:

- fast, convenient online submission

- thorough peer review by experienced researchers in your field

- rapid publication on acceptance

- support for research data, including large and complex data types

- gold Open Access which fosters wider collaboration and increased citations

- maximum visibility for your research: over $100 \mathrm{M}$ website views per year

At $\mathrm{BMC}$, research is always in progress.

Learn more biomedcentral.com/submissions 